\title{
Commentary on Management of Older Inpatients who Refuse Non- Psychiatric Medication
}

\section{Eno Umotong*}

Imperial College London, School of Medicine, London and Heart of England NHS Foundation Trusts, Heartlands Hospital, Birmingham, UK

\section{Commentary}

Almost 60,000 patients were admitted under the mental health act between April 2014 and March 2015 and that number continues to rise every year [1]. Psychiatric patients are known to suffer a greater incidence of physical illness for many reasons, including; medication side effects, lifestyle choices, and disease processes [2]. Cardiovascular disease represents a major cause of morbidity and mortality from physical illness where numerous evidence-based and clinically proven medicines are directed [3]. However, it is this same group of patients where medication non-compliance is among the highest [4]. The consequences of medication non-compliance are significant and include; increased morbidity, early mortality, and financial costs [5]. Despite this, there is little data in the literature to quantify this problem and, more importantly, to offer solutions to this rising conflict.

In the article 'Management of Older Inpatients who refuse NonPsychiatric Medication Within Birmingham and Solihull Mental Health NHS Foundation Trusts', Umotong offers a simple yet effective solution: Communication. The author suggests that a sensitive discussion take place between the patient and duty doctor to explore factors surrounding non-compliance so that attempts can be made to improve medical concordance, as appropriate. Where discussions took place, the author found that changes to compliance and or prescription were brought about in 59\%, compared with $22 \%$ where no consultation occurred. Research spanning many decades has shown how communication is positively correlated to adherence to medical recommendation [6]. One meta-analysis examined 106 correlational studies and 21 experimental interventions between 1949 and 2008 and concluded that poor communication increases the risk of nonadherence by $19 \%$ [7]. Despite this body of evidence, communication is frequently neglected in clinical practice [8]. It has been suggested that healthcare workers do not fully appreciate the impact communication has on patient behaviour. In an American study involving 74 general Intensivists and 814 randomly selected patients in an outpatient setting, participants were asked to rank nine domains as determinants of the quality of outpatient care. Both groups of participants agreed that 'Clinical Skill' was the most important domain. However, there was a remarkable disagreement on the importance of 'Provision of Information' with patients ranking this domain second and the Intensivists ranking it sixth out of the 12 domains [9].

Umotong goes further to highlight the uniqueness of the psychiatric in-patient environment. According to the health and social care information centre [10], the average length of stay for a psychiatric in patient is 23 days compared to 6.9 days for a patient admitted onto a medical ward [11]. Once the patient has stabilised, their admission could serve as prime opportunity for a medication review. Whilst medication reviews are typically conducted by the GP or in the outpatient's department, this requires active engagement which psychiatric patients typically do not participate in [12]. Initially designed as an audit, Umotong turns the article into a small nonrandomised prospective study considering the effects of doctor-patient communication on medication compliance. Though there are obvious limitations to the study: A modest sample size of 36 patients, Lack of statistical analysis and Failure to describe the crucial aspects to the consultation process in detail.

In a paper by Atreja $\mathrm{A}$, et al. [13] they discuss strategies to improve medication compliance through communication. Of relevance, they mention; Imparting appropriate knowledge; Modifying beliefs; Leaving the bias and Evaluating adherence. Numerous studies have found that patients often have a poor understanding of their prescription [14]. Umotong refers to a phenomenon known as 'Health Literacy: the degree to which individuals have the capacity to obtain, process and understand the basic health information and services needed to make appropriate health decisions [15]. Umotong found that discussions with the duty doctor and patient often unveiled poor health literacy which could be reversed, quickly and easily. As example, the author describes a patient who consulted with the doctor regarding constipation however, the patient later refused the laxative medication when offered to them as they were unaware of the indication. Here, the value of 'Imparting appropriate knowledge' seems clear.

Umotong reported that $6 \%$ of patients refused medication due to delusional fears. It may be more difficult to 'Modify beliefs' with a psychotic component however, attempts should be made nonetheless. This would be consistent with the suggested strategy 'Leaving the bias'. In the article, the author found that $58 \%$ of patients refused to provide reasons for medication non-compliance. Whilst these patients may be considered as unwilling engagers, when consultation did occur within this group of patients, changes to compliance and/or prescription were brought about in $56 \%$ of cases. Medication reviews serve as a platform to 'Evaluate adherence', above all, to ensure that the medication remains appropriate. In the article, the author found that $11 \%$ of patients became non-compliant due to changes in their clinical status. Inappropriate prescriptions are a preventable cause of adverse drug reactions which induce patient harm and increase healthcare costs [16]. A Canadian study found that inappropriate medications directed at older patients outside of the hospital setting cost a total of 419 million Canadian dollars in 2013 [17]. Improvements here could prove invaluable.

There is a 10-25-year reduction in the average life expectancy of patients with severe mental illness, largely due to preventable physical ill health [18]. Communication is a simple intervention and, when undertaken at an appropriate time, could have profound enhancements in patients' quality of life and life expectancy and could generate substantial proceeds for the NHS. Despite the limitations of the

*Corresponding author: Eno Umotong, Imperial College London, School of Medicine, London and Heart of England NHS Foundation Trusts, Heartlands Hospital, Birmingham, UK, Tel: 09679638; E-mail: enoumotong@hotmail.com

Received June 09, 2017; Accepted June 15, 2017; Published June 19, 2017

Citation: Umotong E (2017) Commentary on Management of Older Inpatients who Refuse Non-Psychiatric Medication. J Neurol Disord 5: 348. doi:10.4172/23296895.1000348

Copyright: () 2017 Umotong E. This is an open-access article distributed under the terms of the Creative Commons Attribution License, which permits unrestricted use, distribution, and reproduction in any medium, provided the original author and source are credited. 
Citation: Umotong E (2017) Commentary on Management of Older Inpatients who Refuse Non-Psychiatric Medication. J Neurol Disord 5: 348. doi:10.4172/2329-6895.1000348

article, the message cannot be overlooked: Communication improves compliance.

\section{References}

1. Health and Social Care Information Centre (HSCIC) (2015) Uses of the Mental Health Act: Annual Statistics.

2. De-Hert M, Correll CU, Bobes J, Cetkovich-Bakmas M, Cohen D, et al. (2011) Physical illness in patients with severe mental disorders. Incidence, prevalence, impact of medications and disparities in health care. World Psychiatry 10: 52-77.

3. Gladigau EL, Fazio TN, Hannam JP, Dawson LM, Jones SG (2014) Increased cardiovascular risk in patients with severe mental illness. Intern Med J 44: 65-69.

4. Nageotte C, Sulliman G, Duan N, Camp PL (1997) Medication compliance among the seriously mentally ill in a public health system. Soc Psychiatry Psychiatr Epidemiol 32: 49-56.

5. luga AO, McGuire MJ (2014) Adherence and health care costs. Risk Manag Health Policy 7: 35-44.

6. Institute for Healthcare Communication (IHC) (2011) Impact of communication in healthcare.

7. Zolnierek KBH, Di-Matteo MR (2009) Physician communication and patient adherence to treatment: a meta-analysis. Med Care 47: 826-834.

8. Taran S (2011) An examination of the factors contributing to poor communication outside the physician-patient sphere. Mcgill J Med 13: 86
9. Laine C, Davidoff F, Lewis CE, Nelson EC, Nelson E, et al. (1996) Important elements of outpatient care: A comparison of patients' and physicians' opinions. Ann Intern Med 125: 640-645.

10. Health and Social Care Information Centre (HSCIC) (2014) Mental Health Bulletin, Annual Report from MHMDS Returns 2013-2014. Available online [ http://content.digital.nhs.uk/catalogue/PUB15990].

11. NHS confederation (2017) Key statistics on the NHS. Available online [http:// www.nhsconfed.org/resources/key-statistics-on-the-nhs].

12. Dixon LB, Holoshitz Y, Nosse I (2016) Treatment engagement of individuals experiencing mental illness: review and update. World Psychiatry 15: 13-20.

13. Atreja A, Bellam N, Levy SR (2005) Strategies to enhance patient adherence: Making it simple. Med Gen Med 7: 4.

14. Graham S, Brookey J (2008) Do patients understand? Perm J 12: 67-69.

15. Nielsen-Bohlman L, Panzer AM, Kindig DA (2004) Health literacy: A prescription to end confusion. Washington, DC. National Academies Press.

16. Rambhade S, Chakarborty A, Shrivastava A, Patil UK, Rambhade A (2012) A survey on polypharmacy and use of inappropriate medications. Toxicol Int 19: 68-73.

17. Morgan SG, Hunt J, Rioux J, Proulx J, Weymann D, et al. (2016) Frequency and cost of potentially inappropriate prescribing for older adults: A crosssectional study. CMAJ Open 4: E346-E351.

18. Laursen TM, Munk-Olsen T, Vestergaard M (2012) Life expectancy and cardiovascular mortality in persons with schizophrenia. Curr Opin Psychiatry 25: 83-88. 